\title{
Analysis of Trends in Demand for Computer-Related Skills for Academic Librarians from 1974 to 1994
}

\section{Yuan Zhou}

By means of content analysis, this study examines 2,500 employment advertisements for academic librarian positions in 1974, 1979, 1984, 1989 , and 1994 to investigate patterns and trends in the demand for computer-related skills for academic librarians over a period of two decades. The study identifies basic computer-related qualifications required for different types of positions, and tracks changes in the demand for these qualifications over time. It also tests the relationship among size of library, type of position, and degree of demand for computer-related skills. Using a quantitative approach, the study measures the changes brought by computer applications in terms of what qualifies an individual to be an academic librarian.

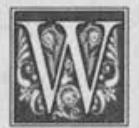

hen comparing the current work environment for academic librarians to that of two decades ago, one finds that among the numerous changes that have occurred, the most visible is perhaps the steady increase in computerization of library services. Replacing many of the paper-based manual processes and enhancing the services in a variety of ways to a higher-than-ever level, computers and computer facilities systems, databases, networks, and other equipment are everywhere in today's academic libraries.

As the application of computers to library operations increased, library managers began to make efforts to recruit individuals with relevant computer expertise. ${ }^{1,2}$ Consequently, computer-related skills changed from some esoteric under- ground specialty to one of the most visible concerns in the profession. ${ }^{3}$

Although it is commonly accepted that the demand for computer-related skills for academic librarians increased significantly over time, there has been no systematic study in tracing the "footsteps" of such a far-reaching change in what qualifies a person to be an academic librarian in the computer age. Basic data analysis on this important change is particularly lacking. A literature search by the author reveals that despite the numerous articles on computer applications in libraries now being published, few studies have applied a quantitative approach to measure the impact of the change on the librarian's job responsibility and competency. Among the few identified, most focused only on a short period of time. ${ }^{4}$

Yuan Zhou is Head of the East Asian Library at the University of Minnesota; e-mail: y-zhou@tx.umn.edu. 
It is precisely this lack of systematic study with data measurement support on the issue that the present study aims to rectify.

Working with data derived from advertisements for positions in academic libraries, the author focused on identifying the types of academic library positions that require computer-related qualifications, describing the kind of computer knowledge and skills that each type demands, and analyzing changes of this demand over time.

\section{Methodology}

The author chose position advertisements appearing in American Libraries in 1974, $1979,1984,1989$, and 1994 as the data source. The study applied content analysis to all advertisements of academic library positions for the years chosen except for those of part-time, nonprofessional, or foreign country positions. The advertisements requiring direct contact with an institution to obtain position descriptions also were excluded. The study recorded relevant information collected from each advertisement on a specially devised Information Coding Form (available from the author).

The author first conducted a pilot examination of 350 advertisements in the pool to identify various types of computer-related requirements appearing in the advertisements. Based on results from the pilot study, the author developed a checklist of computer-related qualifications for data coding. These qualifications include knowledge of, or experience with, the following aspects:

1. bibliographic utilities, such as OCLC or RLIN;

2. automated library systems, including general knowledge of library automation;

3. online database searching, such as DIALOG or BRS;

4. microcomputer applications;

5. mainframe computer applications;

6. CD-ROM products;
7. computer languages or programming;

8. computer hardware;

9. possession of a degree in computer science.

The author added four additional aspects to the coding data from 1994 advertisements in order to reflect new developments in technology applications. They include knowledge of, or experience with:

1. networks, such as LAN or WAN;

2. Internet searching;

3. resources in electronic formats;

4. image technology or multimedia.

Because these headings reflecting what appeared in the advertisements are not designed for standardizing the terminology employed but for coding data, they are not all mutually exclusive.

The author formulated five hypotheses to direct the statistical analysis of the study:

1. As the library work environment becomes increasingly computerized, possession of computer-related skills has changed from an incidental issue to a major qualification for all types of academic library positions.

2. Possession of computer-related skills was of greater importance to positions in large academic libraries than to those in smaller ones (but this difference may have diminished over time).

3. Possession of computer-related skills is of greater importance in certain types of positions than in others (though this difference also may have diminished over time).

4. Computer-related skills that are essential to job competency are likely to vary for different types of positions.

5. New computer-related skills are likely to be added to redefine computer literacy for academic librarians as technology advances over time.

The study established "computer skills needed" as the dependent variable. The variable has a dichotomous value, namely yes or no. When any aspect from the list above appeared in an advertisement as a 
"required," "preferred," or "desired" qualification, the variable for that advertisement would carry a yes value. In cases where the aspects were listed in a section of "responsibilities" or "duties" rather than a section of "qualifications" in an advertisement, the variable would still carry a yes value. If no aspects were advertised, the variable would carry a no value.

The study collected data on independent variables from two sources. For the variables "year" and "position type," data came directly from the advertisements. However, the variable "size of library" took its data from the American Library Directory. The author also gathered other information, such as "title of the position," "name of the library," and "state," for each variable as a safeguard against duplication and data-entry errors. The author chose cross-tabulation and the Chi-square test as the instruments to provide descriptive or inferential analysis, and used Statistical Analysis System (SAS) software to conduct data analysis and hypothesis testing. ${ }^{5}$

\section{Findings and Implications}

A total of 2,833 job advertisements from the years sampled compiled the profile of this study. A review for duplicate cases eliminated 223 observations of readvertised positions from the data set. The study also excluded system librarian positions from further testing because possession of a variety of computer skills is an indispensable qualification for all such positions. These adjustments yielded a net data set of 2,500 observations (see table 1).

It is interesting to note that although the total number of advertisements dropped sharply in 1994 compared to 1989 , the proportion of systems librarian positions in- creased from a plateau of about three percent of the net total from 1979 to 1989 , to about eight percent in 1994. This disproportional emphasis of systems positions suggests that despite the budget constraints generally experienced by most academic institutions in recent years, academic libraries shared a greater commitment to filling automation or computer specialist positions than to filling other types of positions.

\section{Overall Increases}

The test result for hypothesis 1 shows that the growth in demand for computer-related skills for academic librarians was remarkable for the twenty years studied. In 1974, nine out of ten advertisements $(89.7 \%)$ did not list any computer-related qualifications. By 1994, however, the situation had reversed, with 88.9 percent of advertised positions requiring one or more forms of computerrelated skills. The Chi-square test determined that a statistically significant difference existed among these five years regarding advertised demand for computer-related knowledge and skills (see figure 1).

The most dramatic change took place in the late 1970s, when inclusion of computer-related requirements in advertisements rose from 10.3 percent of the total advertisements in 1974 to 50.8 percent in 1979. The considerable increase continued after 1979, attaining 74.2 percent of the total by 1984 . From 1984 to 1994 , the pro-

\begin{tabular}{|crrrr|}
\hline \multicolumn{5}{c|}{ TABLE 1 } \\
Position Advertisements by Year \\
\hline \hline Year & Gross total & Duplicates & $\begin{array}{l}\text { Systems } \\
\text { positions }\end{array}$ & Net total \\
\hline 1974 & 132 & 34 & 1 & 97 \\
1979 & 406 & 33 & 13 & 360 \\
1984 & 673 & 42 & 23 & 608 \\
1989 & 1,082 & 93 & 30 & 959 \\
1994 & 540 & 21 & 43 & 476 \\
\hline Sum & 2,833 & 223 & 110 & 2,500 \\
\hline
\end{tabular}




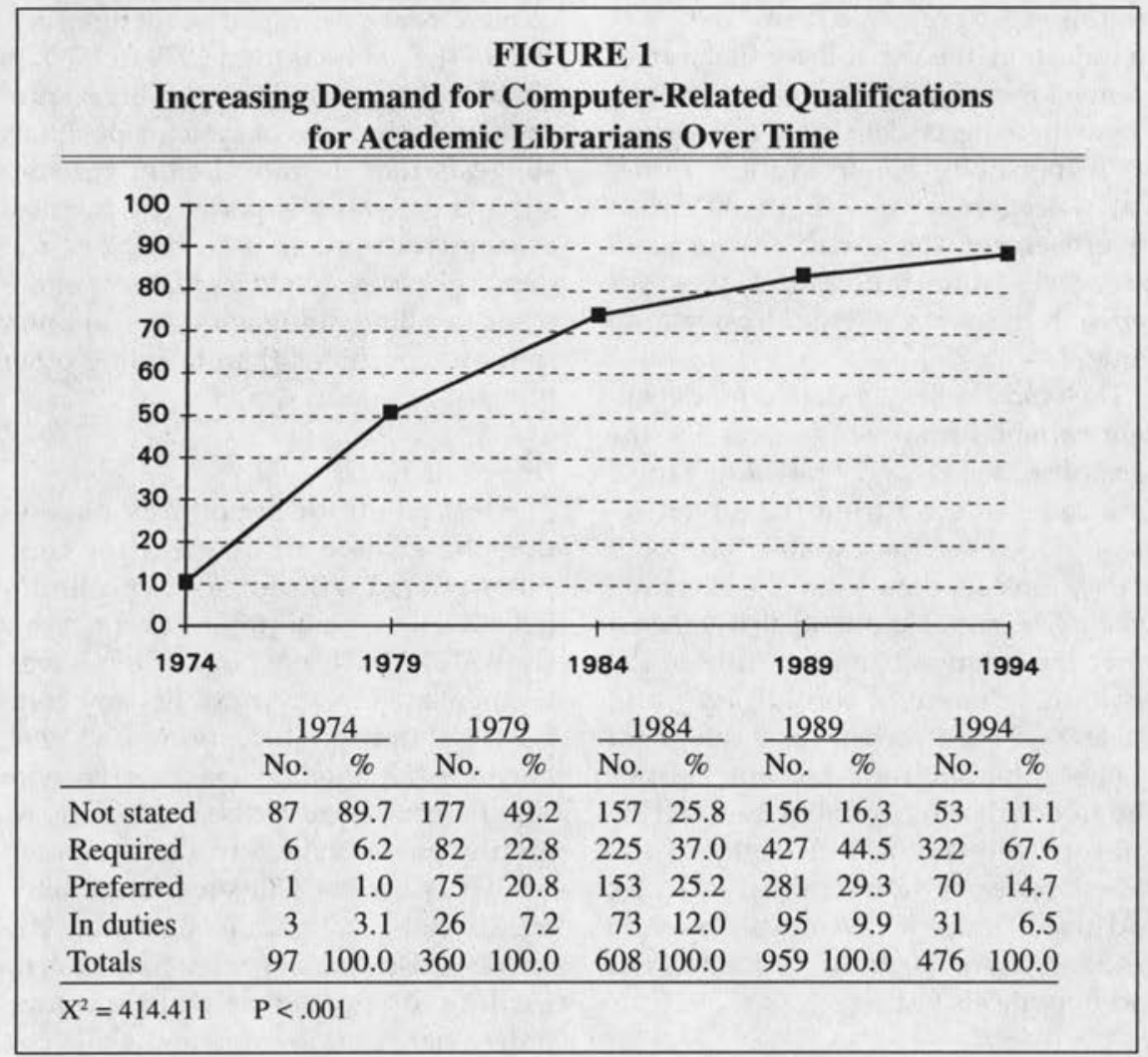

portional growth of the advertisements listing computer-related qualifications does not seem as impressive as it does for the period of 1974 to 1984 . However, this does not necessarily imply that the diffusion of computer applications slowed down in academic libraries for the period. It should be noted that the variable "computer skills needed," carrying a dichotomous value, measures only a yes-no situation for each position. The variable could not measure the breadth of computer-related skills needed for a position. It is mostly in this dimension, as discussed later in this study, that the demands for computer-related skills for academic librarians continued to grow in the late 1980 s and early 1990 s.

\section{Size of Library}

The study categorized all libraries into four groups based on the size of their volume holdings in the thousands:

- Size 1 1-349

- Size 2 350-999

- Size 3 1,000-1,999

- Size $4 \quad 2,000$ and above

Because position advertisements rarely include information on the size of an institution's collection, the author derived data from the American Library Directory. The study calculates a library's collection based on its book and bound-periodical holdings only because statistics for other materials are often unavailable or incomplete in the Directory. There were two cases in 1974, three in 1979, seven in 1984 and 1989, and four in 1994 that were excluded from this test on hypothesis 2 because the Directory provided no holdings 
information for these libraries (see table 2).

The results of this test were surprising. Contrary to the hypothesized expectation that large libraries were more likely to demand computer-related qualifications for librarians, the results of the Chi-square tests on the data from 1979, 1984, 1989, and 1994 were all statistically insignificant when setting alpha at 0.01 . The test could not be applied to data from 1974 because the values of the expected frequency in several cells were too low to meet a validity requirement of the Chisquare test. ${ }^{6}$ Nevertheless, the descriptive statistics produced indicate that the larger libraries did not post proportionally more advertisements listing computer-related requirements in 1974 than the smaller libraries. These results suggest that the degree of demand for librarians with computer skills has little to do with the size of a library. Caution must be exercised in making this generalization, however, as the variable used in this test cannot measure the breadth of the computer skills a position may require. Difference in this aspect may exist between larger and smaller libraries.

\section{Type of Position}

The author divided all positions into four categories: (1) technical services division, including positions for acquisitions, cataloging, serials, preservation, and collection management; (2) public services division, including positions for reference, bibliographic instruction, circulation, document delivery, and interlibrary loan (ILL); (3) administrators division, including deans, university librarians, directors, and assistant or associate directors who have general management responsibilities; and (4) branch librarians and specialists division, including branch librarians, government document librarians, bibliographers, area specialists, curators, and archivists. Although more subdivisions may be applicable to some of these categories (e.g., division 4), the study did not

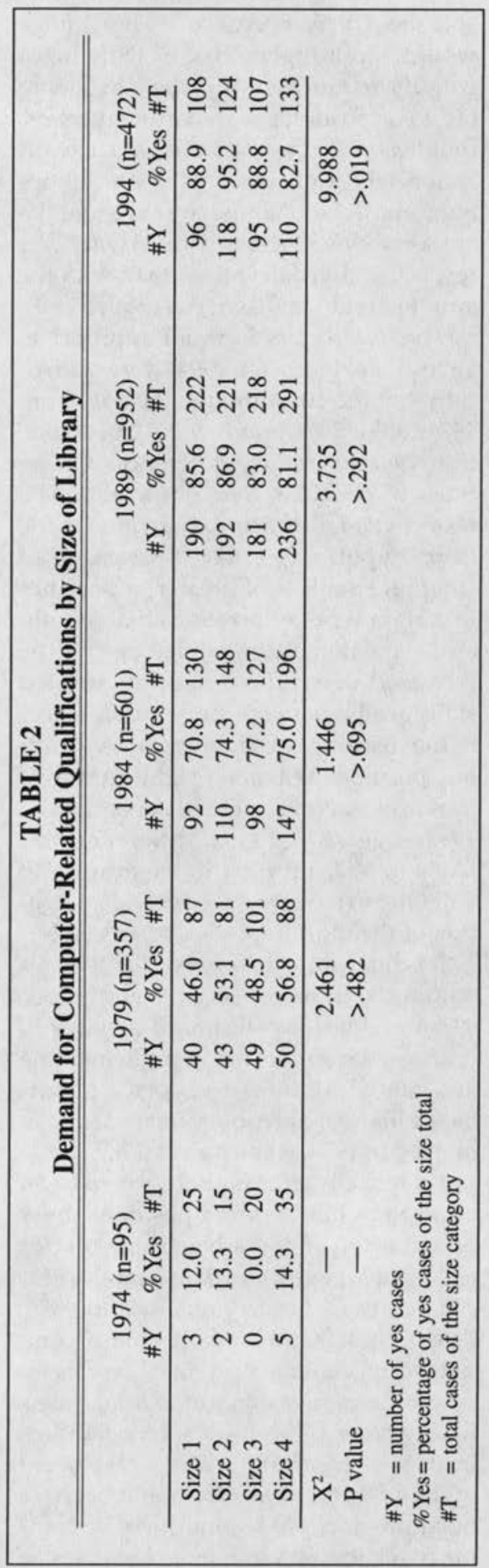


split them further because smaller groups would run a higher risk of violating a validity requirement for the Chi-square test. ${ }^{7}$ For positions of department heads, unit heads, and assistant or associate directors whose managerial responsibilities are confined to mainly one division, the author decided to classify them with their respective divisions rather than with the administrators division (see figure 2).

The test results from all appropriate years, namely 1979 to 1994 , were statistically significant. Although the data from 1974 could not support a valid Chi-square test, the considerable differences among types of positions were observable. The results validate the first contention of the third hypothesis-that "possession of computer skills is of greater importance in certain types of positions than in others"- and demonstrated that despite the increased demand for computer-related skills in all types of positions, differences in the degree of desirability among various positions remained significant over these years. Nevertheless, the data from 1994 suggest that such differences are likely to lessen further in the future and validate, to a degree, the second contention of the third hypothesis as a trend.

It is interesting to observe the changes within the technical services and public services divisions. Technical services librarians were pioneers in implementing automated systems to replace paperbased manual operations in academic libraries. In 1974, when possession of computer-related skills did not seem to be an issue to public services positions, over one-quarter of the advertisements for technical services positions searched for candidates with such a qualification. The data suggest that at the early stage of computer applications, academic libraries focused their efforts on automating internal operations. This focus soon expanded. In 1979, after just five years, 42.9 percent of the advertisements for public services positions included some form of computer-related requirements. Increases of such requirements among the advertisements for technical services positions, however, were even more impressive for the period, demonstrating that as academic libraries strove to expand automation of the internal operations, they also made substantial efforts to extend the benefits of computerization to their patrons. By 1989, the proportions of the advertisements demanding computer-related qualifications were almost identical in the two divisions, resulting from greater increases of such advertisements in the public services division from 1979 to 1989 . The greater increases indicated that the focus of the expanding computerization gradually shifted to public services functions.

\section{Position Preference for Computer Skills}

Differences among types of positions may reside not only in the degree of desirability for computer-related qualifications, but also in the kind of computer knowledge or skills specified in the advertisements. As hypothesis 4 proposed, each type of position tends to have its own preference for certain computer skills. This analysis examines what kinds of computer skills were most relevant to each type of position by studying the frequency of a variety of computer skills specified in the advertisements for different position types. The author included only the advertisements listing at least one form of computer-related qualification in this analysis. The frequency for each computer-related qualification was calculated in proportion against the total number of relevant advertisements for a given position type within a given year. Because many advertisements, particularly in later years, listed more than one such qualification, the total of the proportions for all applicable qualifications for a position type within a year may exceed 100 percent (see table 3 ).

Differences in preference for certain kinds of computer knowledge or skills 


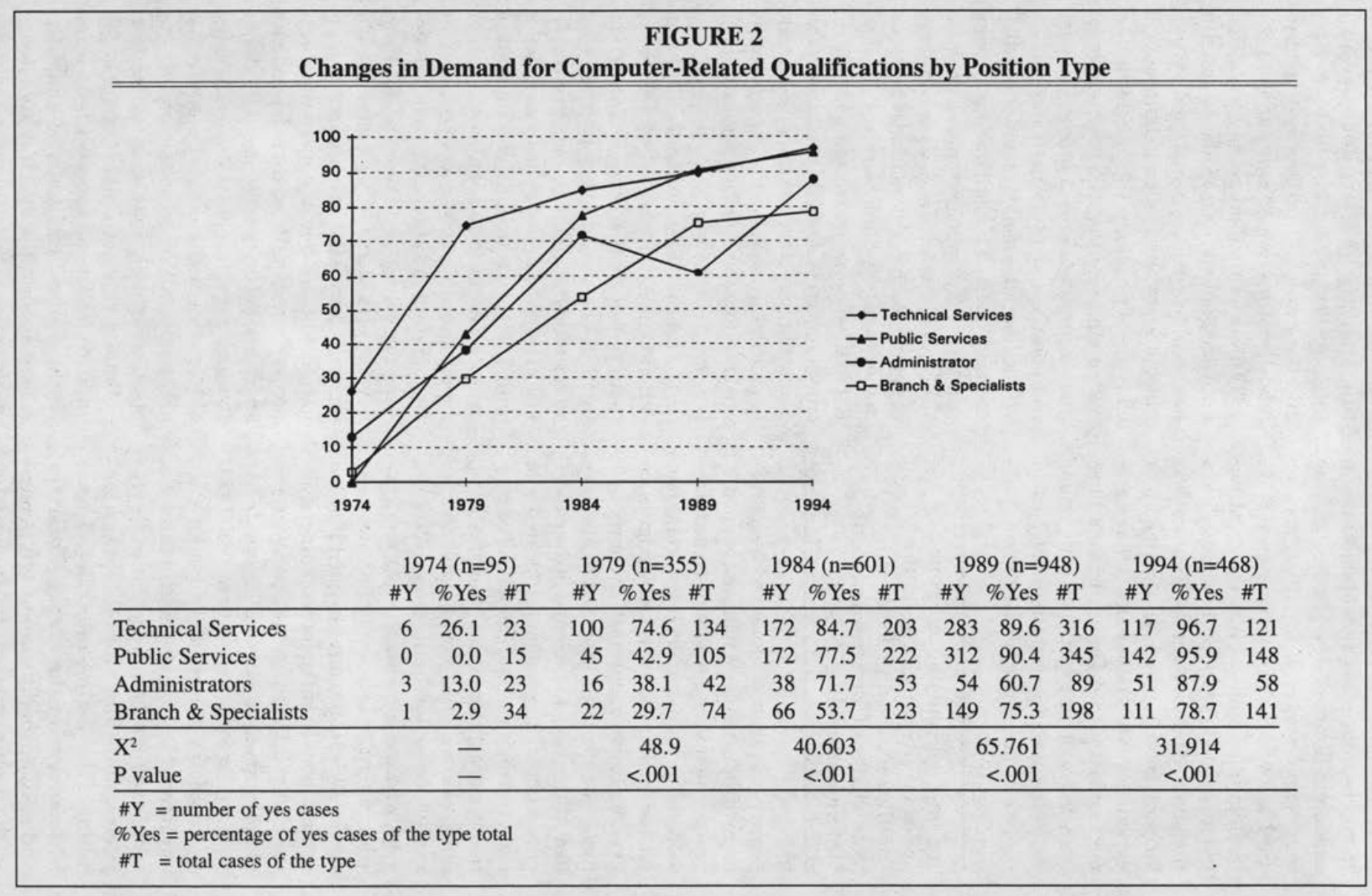


among different types of positions assert themselves once computer applications in academic libraries develop beyond the embryonic stage. From 1979 through 1989 , knowledge of, or experience with, bibliographic utilities was the most frequently listed computer-based qualification among positions in the technical services division, whereas knowledge of, or experience with, automated library systems ranked second. During the same time, knowledge of, or experience with, online searching was the most frequently listed computer-related requirement among pub-

\section{In 1994, one out of every four relevant advertisements in the public services division listed knowledge of, or experience with, Internet searching, ...}

lic services positions, followed by knowledge of, or experience with, automated library systems. In the administrators division, the most frequently listed computerrelated qualification was knowledge of, or experience with, automated library systems. For the branch librarians and specialists division, knowledge of, or experience with, online searching appeared in at least one-half of the relevant advertisements during this period. Knowledge of, or experience with, bibliographic utilities ranked second for the division in 1979 and 1984, whereas knowledge of, or experience with, automated library systems was second in 1989. These most frequently listed qualifications were the core computer skills for academic librarians in respective types of positions to have for the period.

A major change occurred in 1994, when knowledge of, or experience with, automated library systems became the most frequently listed computer-related qualification for all types of positions. The listing rate ranged from 81.1 percent in the branch librarians and specialists division to 100 percent in the administrators division among the relevant advertisements used in this analysis. A sharp increase was most observable in the public services and the branch librarians and specialists divisions when compared to the 1989 data. This change suggests that knowledge of automated library systems has become a generic component of computer literacy for academic librarians in all types of positions. Despite the uniformity on this requirement, preferences for other computer skills continued to vary from one type of position to another.

The computer-related qualifications that are needed for academic librarians to maintain their job competency also have been augmented by advances in technology over time. Such augmentation is best seen in the case of the public services division. Rapid development in introducing microcomputers and CD-ROM products to academic libraries since the mid-1980s made knowledge in these aspects important new qualifications for librarians within the public services division.

The four items added to the list to accommodate data from 1994 give the study more power in analyzing recent trends. In 1994, one out of every four relevant advertisements in the public services division listed knowledge of, or experience with, Internet searching, and one out of every seven included knowledge of, or experience with, networks as required or desirable qualifications. As a natural consequence of increased demand for these new aspects, demand for online searching skills declined. Clearly, as more alternative sources became available, academic libraries reduced their dependence on traditional online services. If this trend continues, it seems likely that knowledge of Internet searching may become a major component of computer literacy for positions in the public services division.

Similar changes also occurred in the branch librarians and specialists division. As the demand rose for new computerrelated qualifications such as knowledge of, or experience with, microcomputer 
applications and CD-ROM products, the demand for previously high-ranking skills such as online searching and bibliographic utilities declined. This trend of a growing need for new computer-related skills also is reflected in the emergence of a demand for knowledge of Internet searching $(18.9 \%)$ and resources in electronic formats $(12.6 \%)$. In fact, the demand for knowledge of resources in electronic formats - one of the newest computer-related qualifications-was found more often in the advertisements of this division than in any other. An important contributor to this fact was the change occurring in requirements for bibliographers. Previously, computer-related skills received less emphasis for bibliographers than for many other types of academic librarian positions. ${ }^{8}$ However, recent trends indicate a change. An analysis of the advertisements for bibliographer positions revealed that in $1989,37.5$ percent included at least one computer-related qualification. That number increased to 58.8 percent by 1994 . Among these cases, one-half specified knowledge of resources in electronic formats.

As might be expected, computer-related requirements for positions in the technical services division experienced the fewest changes over the time observed. Knowledge of, or experience with, bibliographic utilities and automated library systems remained the basic computer-based qualifications for positions in this division. The demand for a newer skill-knowledge of, or experience with, microcomputer applications-is still quite moderate, though slowly increasing. It appears that the division that experienced the earliest upheaval from computer applications entered a period of relative stability, compared to the other divisions. If, however, publications in electronic formats live up to predictions that they will become major aspects of scholarly communication, requirements for technical services positions will naturally change in response to this development. ${ }^{9}$
Advertisements for positions in the administrators division consistently listed knowledge of automated library systems as their major component of computer literacy, whereas knowledge of bibliographic utilities - in high demand during the early stages of library automation-decreased in frequency in this division during the time observed. Recent trends in the escalating demand for knowledge of microcomputer applications, Internet searching, and networks may suggest something of the direction computer-related requirements could take for the next generation of academic library administrators.

\section{Multiple Requirements}

Change also can be measured by the increases in advertisements listing multiple requirements for computer-related qualifications over the years observed. This measurement offers some useful data to analyzing the breadth of computer-related skills demanded for the various position types. Because no advertisements with multiple requirements appeared in 1974, the author excluded that year from the analysis, as well as the year 1979, for the branch librarians and specialists division (see table 4).

Cross-tabulation provides a useful comparison of the technical services division with the public services division. The data demonstrated that in the early years of computer applications, advertisements for technical services positions were more likely not only to require computer-related skills but also to demand a broader range in such qualifications than advertisements for public services positions. In 1984, 21.5 percent of the relevant advertisements for technical services positions specified two or more computerrelated qualifications, whereas only 11 percent of public services positions did so. However, this difference virtually disappeared in 1989, when advertisements listing multiple requirements in both divisions were nearly equal at 43.5 and 44.2 percent, respectively. In addition, adver- 


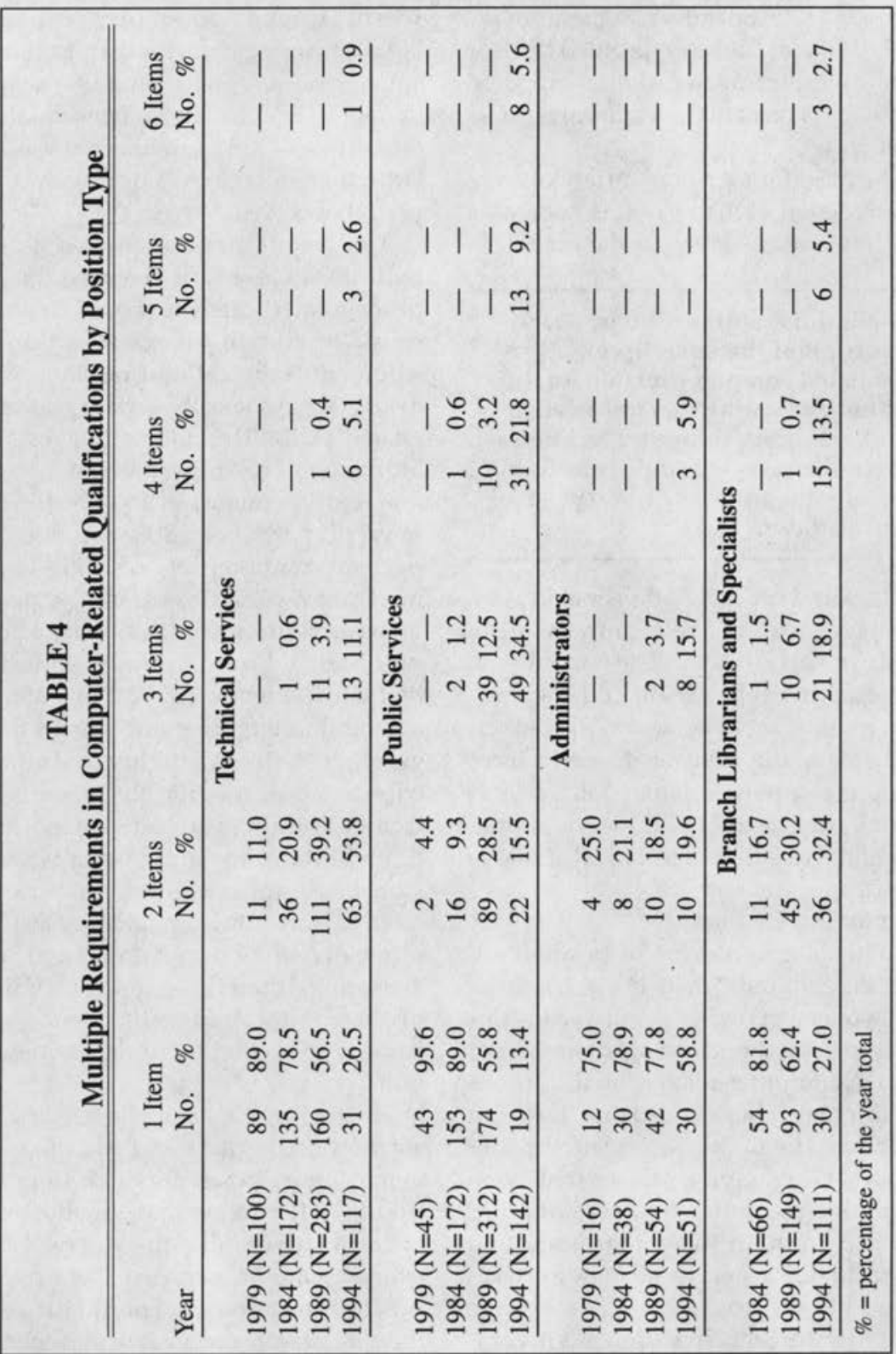

tisements specifying three or more computer-related skills attained a considerably larger share in the public services division at 15.7 percent than they did in the technical services division at 4.2 percent. As discussed previously, this change is attributable largely to the increased use of microcomputers and CD-ROM products in the public services environment. Thus, by 1989 , advertisements for public services positions listed a wider variety of computer-related qualifications than those for technical services. This trend continued, and in 1994, more than 70 per- 
cent of the relevant advertisements in the public services division specified three or more computer-related skills, compared to only 20 percent in the technical services division.

The need for a greater variety of computer-related skills also was seen as a trend among positions in the branch li-

\section{For administrator positions, nearly 88 percent of the advertisements in 1994 listed computer-related qualifi- cations, indicating that knowledge ... of emerging computer technolo- gies in libraries is a highly desirable attribute for academic library administrators.}

brarians and specialists division. In 1989, 38.6 percent of the relevant advertisements in this division listed more than one computer-related skill. In 1994, however, more than 40 percent of the advertisements in this division specified three or more computer-related skills, a level second only to the public services division and twice that of technical services.

\section{Concluding Remarks}

By analyzing four years of position advertisements published in American $\mathrm{Li}$ braries over a period of twenty years, this study tracks the growing demand for various computer-related qualifications for different types of academic librarian positions. The findings validate the contention of the first hypothesis that "possession of computer-related skills has changed from an incidental issue to a major qualification for all types of academic library positions." The change demonstrates that developments in computer applications have had a sweeping impact on attitudes toward computer literacy in academic libraries.

The results of testing the relationship between the demand for computerrelated qualifications and size of libraries invalidate the second hypothesis that "possession of computer-related skills was of greater importance to positions in large academic libraries than to those in smaller ones." The tests show that the demand for computer-related qualifications in small academic libraries was similar to that in large ones during the entire period observed.

The type of position proved a useful indicator in assessing the need for computer-related qualifications. Generally speaking, current advertisements for positions in technical and public services nearly always specify certain computerrelated skills. The finding suggests that individuals seeking a career in these two major divisions of academic libraries must prepare themselves by obtaining relevant computer-related skills. For administrator positions, nearly 88 percent of the advertisements in 1994 listed computer-related qualifications, indicating that knowledge of applications of available and emerging computer technologies in libraries is a highly desirable attribute for academic library administrators. Although advertisements in the branch librarians and specialists division have not specified computer-related skills to the same degree as in the other divisions, the data show that in 1994 , more than three-quarters $(78.7 \%)$ of the net total advertisements listed some type of computer-related qualifications.

An investigation into the relevance for a variety of computer-related skills to academic library positions yields important findings. It reveals that for most computer-related skills, the degree of relevance tends to vary from one type of position to another. The qualification most frequently specified in the advertisements of all types of positions is knowledge of, or experience with, automated library systems, indicating that, for the present time at least, this qualification is the most readily transferable computerrelated skill among academic library positions. The investigation also found that the scope of computer-related skills for 
academic librarians is augmenting as technology and applications develop. As a result, the degree of importance attached to some particular skills at a given time may change, giving way to the latest development.

By examining the frequency of advertisements listing multiple requirements over time, the study revealed that the majority of the advertisements demanding computer-related skills have changed during the period observed, from asking for only one form of the skills to asking for multiple skills. This change is attributable to recent developments in electronic publishing and the application of network technology. The continued increase in the use of microcomputers and CD-ROM products in academic libraries also is an important contributor. According to the data from 1994, positions for public services librarians were more likely to demand multiple requirements than positions in any other division.

While identifying the most relevant computer-related qualifications for each type of position, the study also disclosed that certain qualifications appeared in advertisements only rarely over the time observed. These include knowledge of, or experience with, mainframe computer applications, computer languages and programming, computer hardware, and possession of a degree in computer science. It appears that these qualifications are required almost exclusively for systems librarian positions. One additional item rarely listed in the advertisements is knowledge of, or experience with, im- age technology and multimedia. The infrequent appearances of this requirement in the advertisements may reflect the relatively recent development of this computer application.

The study clearly demonstrated that computer applications have never stopped advancing in academic libraries, nor has the demand for computer-literate librarians. This situation presents a great challenge to the entire profession. Library schools must enrich their automation curricula to reflect new developments and to meet the increasing demand for computer-literate graduates. Libraries must continue their efforts to provide programs of professional development and on-the-job training to enhance employees' computer-related skills. However, improvement of librarians' computer literacy depends ultimately on librarians themselves. They must take initiatives to build their basic computer literacy and keep up with new skills as they develop, because the future of academic librarianship will certainly rely more, and not less, on the development of computer applications in libraries.

Note: The author wishes to express his sincere appreciation to Linda C. Smith, Kathryn Luther Henderson, and Bryce Allen of the University of Illinois at Urbana-Champaign for their invaluable guidance with this research. The author also is gratefully in debt to Calvin Elliker at the University of Michigan Libraries, whose numerous editorial remarks helped greatly in shaping the final draft of this paper.

\section{Notes}

1. Karen L. Horny, "Managing Change: Technology \& Profession," Library Journal 110 (Oct. 1985): 56.

2. S. Michael Malinconico, "Librarians in an Age of Technology," Library Administration \& Management 3 (summer 1989): 143.

3. Susan Baerg Epstein, "Suddenly Last Decade! Automation Arrives," Library Journal 108 (Feb. 1983): 183.

4. For example, David Block, Emerging Personnel Requirements in Academic Libraries As Reflected in Recent Position Announcements, ERIC, ED 215703 (Washington, D.C.: ERIC Document Reproduction Service, 1985); Phyllis J. Hudson, "Recruitment for Academic Librarianship," in 
Librarians for the New Millennium (Chicago: ALA Office for Library Personnel Resources, 1988); and David W. Reser and Anita P. Schuneman, "The Academic Library Job Market: A Content Analysis Comparing Public and Technical Services," College \& Research Libraries 53 (Jan. 1992): 49-59.

5. SAS is the trademark of the SAS Institute Inc., Cary, North Carolina.

6. The Chi-square test requires that the value of expected frequency ( $f_{e}$ ) for each cell in the test be at least five. See Donald Byrkit, Statistics Today: A Comprehensive Introduction (Menlo Park, Calif.: Benjamin/Cummings Publishing Co., 1987), 502.

7. Ibid.

8. Yuan Zhou, "From Smart Guesser to Smart Navigator: Changes in Collection Development for Research Libraries in a Network Environment," Library Trends 42 (spring 1994): 649.

9. Eldred Smith and Peggy Johnson, "How to Survive the Present While Preparing for the Future: A Research Library Strategy," College \& Research Libraries 54 (Sept. 1993): 389-96.

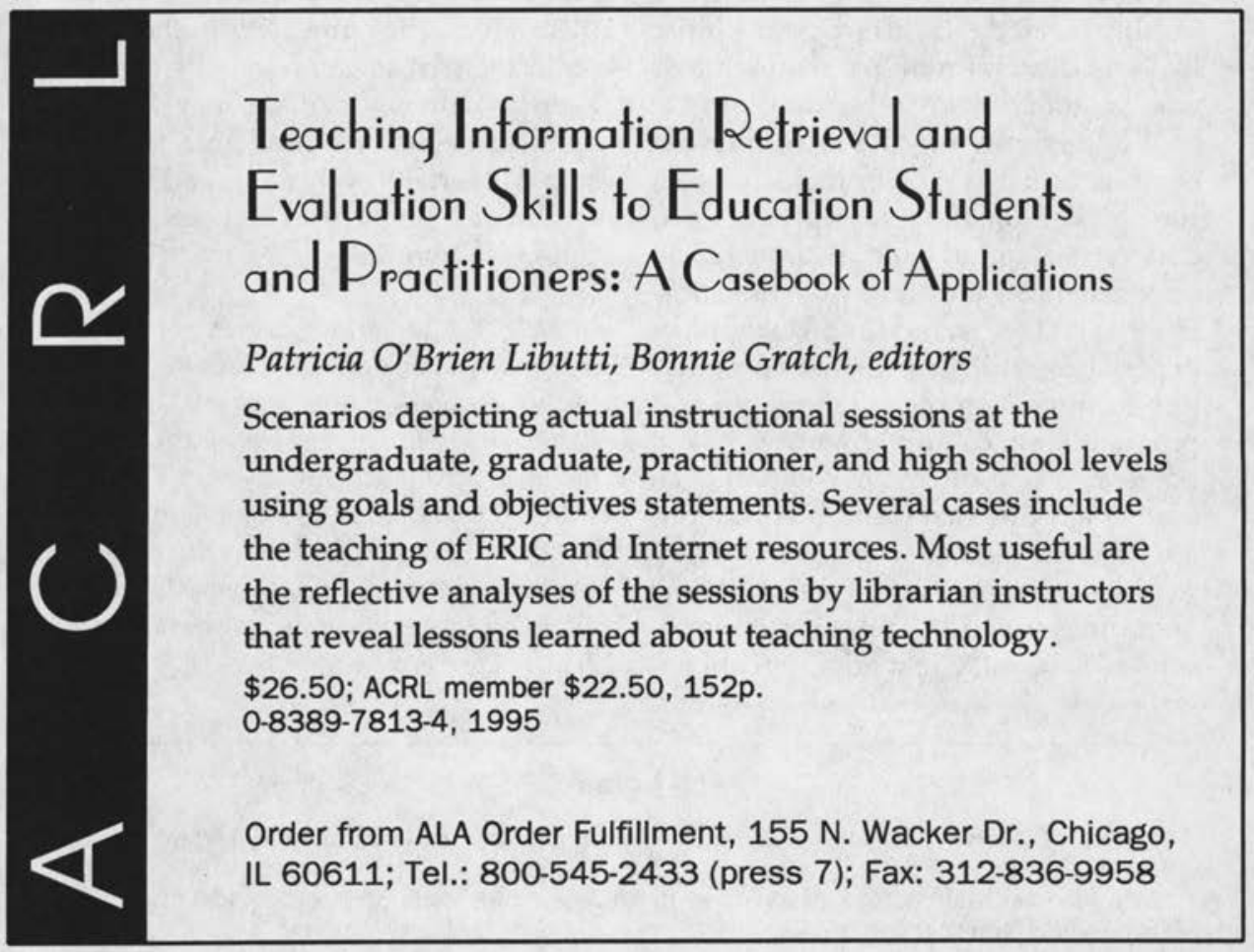




\section{The State \\ of the Art}

Leaders in the Information

...working

smart
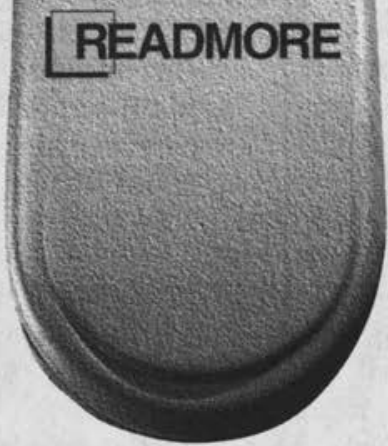

Industry providing subscription

services, article delivery and

library automation software.

$\boldsymbol{R E M o}^{\circledR}$ Mouse driven serials management system.

Ross ${ }^{\circledR}$ Online ordering, claiming and searching of journal and . publisher databases.

RENEWAL EXPRESS PC-based system to analyze current serials holdings and plan for future collection development.

Financial Planner Lotus formatted worksheet to analyze previous spending history and plan future budget allocations.

BACKSERV/BACKMED An Internet list solely devoted to the informal exchange of serial back issues among libraries.

WORLD WIDE WEB

http://www.readmore.com

\section{Readmore ACademic Services}

700 Black Horse Pike, Suite 207

Blackwood, NJ 08012

Phone: 1-800-645-6595

Fax: 609-227-8322 